\title{
New Oribatid Mites of the Genus Epidamaeus (Acari: Oribatida: Damaeidae) from Mongolia
}

\author{
Badamdorj Bayartogtokh \\ Department of Soil Zoology, Institute of Environmental Science and Technology, \\ Yokohama National University, Yokohama, 240-8501 Japan \\ Permanent address: Department of Zoology, Faculty of Biology, \\ National University of Mongolia, Ulaanbaatar, 210646 Mongolia
}

(Received 5 April 2000; Accepted 4 August 2000)

\begin{abstract}
Three new species of oribatid mites belonging to the genus Epidamaeus are described from Mongolia. Epidamaeus granulatus sp. nov. differs from its closely related species in the presence of three setae on trochanter III, the strongly curved spinae adnatae directed anteromedially, and the very thick and strongly barbed notogastral setae. Epidamaeus culterisetosus sp. nov. can be distinguished from its congeners by the table-knife-like notogastral setae of the $d, l$, and $h$ series; the distally expanded sensilli; the absence of prodorsal tubercles $D a$ and $B p$; the relatively long and distally projected tubercle $S p$; the different direction of the spinae adnatae; the long posterior notogastral setae $p s_{1}, p s_{2}$, and $p s_{3}$; the smooth epimeral and ano-genital setae; and the different number of setae on tarsi I, III, and IV. Epidamaeus mongolicus sp. nov. is easily distinguishable from the other known species by the strongly developed tectum of the podocephalic fossa, the presence of three pairs of well developed prodorsal tubercles $(B a, B b$, and $D a)$, and the absence of enantiophyses $E 2$ and $V$.
\end{abstract}

Key Words: Acari, Oribatida, Damaeidae, Epidamaeus, new species, Mongolia.

\section{Introduction}

Oribatid mites of the genus Epidamaeus are known to be very diverse throughout the Northern Hemisphere. Representatives of this genus have been described and recorded mostly from the Palaearctic and Nearctic Regions. According to present knowledge, the genus appears to be poorly represented in the Southern Hemisphere, where a few species have been described from the Neotropical Region.

The known diversity of Damaeidae is greatest in Europe and some parts of Asia, but the Mongolian damaeid fauna remains completely unknown. Judging from collections of damaeid mites made recently in different regions of Mongolia, this country appears to be as species-rich as other parts of Palaearctic.

The present work is part of a series of studies on the oribatid mite fauna of Mongolia, and it is the second report concerning the genus Epidamaeus. The results of studies on the other damaeids of Mongolia will be published in further works. 


\section{Material and Methods}

All three species were collected in 1996 from the litter of birch and larch forests and soils of mountain steppe habitats in central Mongolia. The type locality and habitat characterization for each species are given in the respective "Material examined" sections. Immature stages are unknown for all of these species.

The morphological terminology used in this paper is based on that (with a few modifications) developed by Grandjean (1960), Norton (1977b, 1978, 1979), and Behan-Pelletier and Norton $(1983,1985)$. The nomenclature of leg setation is summarized by Norton (1977a). The abbreviations for morphological structures of idiosoma and leg setations are shown in Figs 1-10.

All measurements are given in micrometers $(\mu \mathrm{m})$, and the average measurement values are given in parentheses after the ranges. Body length is measured in lateral view, from the tip of the rostrum to the posterior edge of the ventral plate, to avoid discrepancies caused by different degrees of notogastral distension. Proterosomal length is measured in lateral aspect, from the tip of the rostrum to the dorsosejugal groove, which is visible posterior to the bothridium. Proterosomal width is measured in dorsal aspect, from the left edge to the right edge at the level of the bothridia or just in front of acetabulum II. Hysterosomal length is measured in lateral aspect from the dorsosejugal groove to the posterior edge of the ventral plate. Notogastral length is measured in lateral aspect, from the anterior to the posterior edge. Notogastral width refers to the maximum width in dorsal aspect. Hysterosomal dorso-ventral thickness is measured in lateral aspect, from the edge of the ventral plate to the dorsal edge of the notogaster in postgenital transect. Notogastral thickness is measured in lateral aspect, from the dorsal to the ventral edge of the notogaster (see Fig. 3). All measurements of body setae are made in lateral aspect. Length of leg segments is measured in lateral aspect, and includes the portion inserted into the next segment.

\section{Description of Species}

\section{Epidamaeus granulatus sp. nov.}

(Figs 1-10)

Diagnosis. Relatively small species with general characters of Epidamaeus. Propodolateral apophysis $P$ present; prodorsal tubercle $B a$ present, but tubercles $B p, D a$, and $D p$ absent; sensilli long, strongly barbed; notogastral setae very thick, strongly barbed, darkly pigmented; two pairs of posterior setae $p s_{2}$ and $p s_{3}$ very short, thin, minutely barbed unilaterally, about one third as long as other setae; spinae adnatae $(s a)$ large, strongly curved anteromediad; enantiophyses $E 2, V$, and $S$ well developed; epimeral regions III and IV with three and four setae, respectively; seta 1c inserted on large apophysis; both tarsi II and III with 16 setae; trochanter III with three strong setae; leg IV about 1.2 times longer than body.

Measurements. Body length 427-533 (480) $\mu \mathrm{m}$; proterosomal length 162-183 (173) $\mu \mathrm{m}$; proterosomal width 198-213 (205) $\mu \mathrm{m}$; hysterosomal length $305-423$ (364) $\mu \mathrm{m}$; notogastral length 325-396 (360) $\mu \mathrm{m}$; notogastral width 289-335 (312) $\mu \mathrm{m}$.

Description. Integument. Yellowish-brown to deep reddish brown in color. 
Surface of dorsal and ventral plates of body and leg segments with dark granules. Conspicuously microtuberculate on all tubercles, on lateral part of podosoma, and around leg acetabula. Notogaster with numerous round granules; adherent debris and exuvial scalps absent.

Prodorsum. Rostrum broadly rounded in dorsal view, but in lateral view slightly projected anteroventrad (Figs 1, 3). Rostral seta (ro) long (56-61 (58) $\mu \mathrm{m}$ ), finely barbed unilaterally. Lamellar seta (le) long (66-76 (71) $\mu \mathrm{m})$, slightly longer than ro. Interlamellar seta (in) shorter (35-46 (40) $\mu \mathrm{m})$ but thicker than ro or le, densely barbed throughout, slightly dark in color. Exobothridial seta (ex) short $(30-35(33) \mu \mathrm{m})$ but thick, densely barbed. Sensillus (ss) thin but long (152-168 (160) $\mu \mathrm{m})$, strongly barbed throughout its length. Bothridium (bo) irregularly funnelshaped, directed posterolaterad. Pair of weakly developed, short longitudinal ridges situated between insertions of interlamellar setae. Tubercles $B p, D a$, and $D p$ absent, pair of tubercles $B a$ relatively large, widely spaced from each other, situated posterior to each bothridium. Propodolateral apophyses $(P)$ well developed, nearly elongate-triangular in shape, directed anterolaterad (Fig. 1).

Notogaster. Slightly ovate when viewed perpendicular to circumgastric scissure; about 1.09 times as long as wide. Hysterosomal dorso-ventral thickness $218 \mu \mathrm{m}$; notogastral thickness $132 \mu \mathrm{m}$. Spinae adnatae (sa) large $(46 \mu \mathrm{m})$, strongly curved anteromediad, each with broad base and distally tapering, fine tip; distance between their bases approximately equal to that between tubercles $B a-B a$. Posterior two pairs of notogastral setae $p s_{2}$ and $p s_{3}$ very short $(23-26 \mu \mathrm{m})$, about one third as long as other setae, thin, minutely barbed unilaterally (Figs 1,2 ); $p s_{1}$ nearly as long as other setae, but distinctly thinner; remaining notogastral setae very thick, darkly pigmented, and strongly barbed throughout their length $(76-116 \mu \mathrm{m})$. Setae $c_{1}$ directed anterolaterad, other setae directed posterior or posterolaterad. Lyrifissures $\mathrm{ia}$, im, and ip and latero-opisthosomal gland opening gla conspicuously developed, but all of them small; lyrifissures ih and ips inconspicuous (Figs 1, 3).

Gnathosoma. Infracapitular mentum nearly as long as wide, without noticeable microtubercles. Hypostomal setae $h$ very long, setae $m$ medium in length, setae $a$ very short, all of them conspicuously barbed unilaterally (Fig. 2). Chelicerae relatively small $(86 \mu \mathrm{m})$, fixed and movable digits with a few blunt teeth. Trägårdh's organ narrow, almost inconspicuous; setae cha and chb barbed; porose area absent (Fig. 5). Palp slender $(76 \mu \mathrm{m})$, palpal setation: 0-2-1-3-8, including solenidion $\omega$ (Fig. 4).

Epimeral region. Tectum of podocephalic fossa not projected, but slightly rounded under trochanter I. Epimeral tubercles $E 2 a$ and E2p rounded to broadly triangular in ventral view. Parastigmatic tubercles $S a$ and $S p$ and ventrosejugal tubercles $V a$ and $V p$ strongly developed, broadly rounded to subtriangular; $V p$ bearing epimeral seta $3 b$. Discidium ( $d i)$ well developed, nearly triangular. Epimeral setae barbed; epimeral setal formula: 3-1-3-4 (Fig. 2).

Ano-genital region. Structure normal for genus, posterior part of genital plates with a few microtubercles. Ano-genital setae long, barbed. Adanal lyrifissures (iad) situated obliquely, at a level a little anterior to anal setae $a n_{2}$ (Figs 2,3).

Legs. All leg segments with numerous granules as shown on femur I (Fig. 6). Lengths of leg segments shown in Table 1 . Seta $d$ on genu I a little shorter than its coupled solenidion $\sigma$, but on legs II and III both of approximately same length. Trochanter III with three long setae, all strong and roughly barbed (Figs 8, 9). 

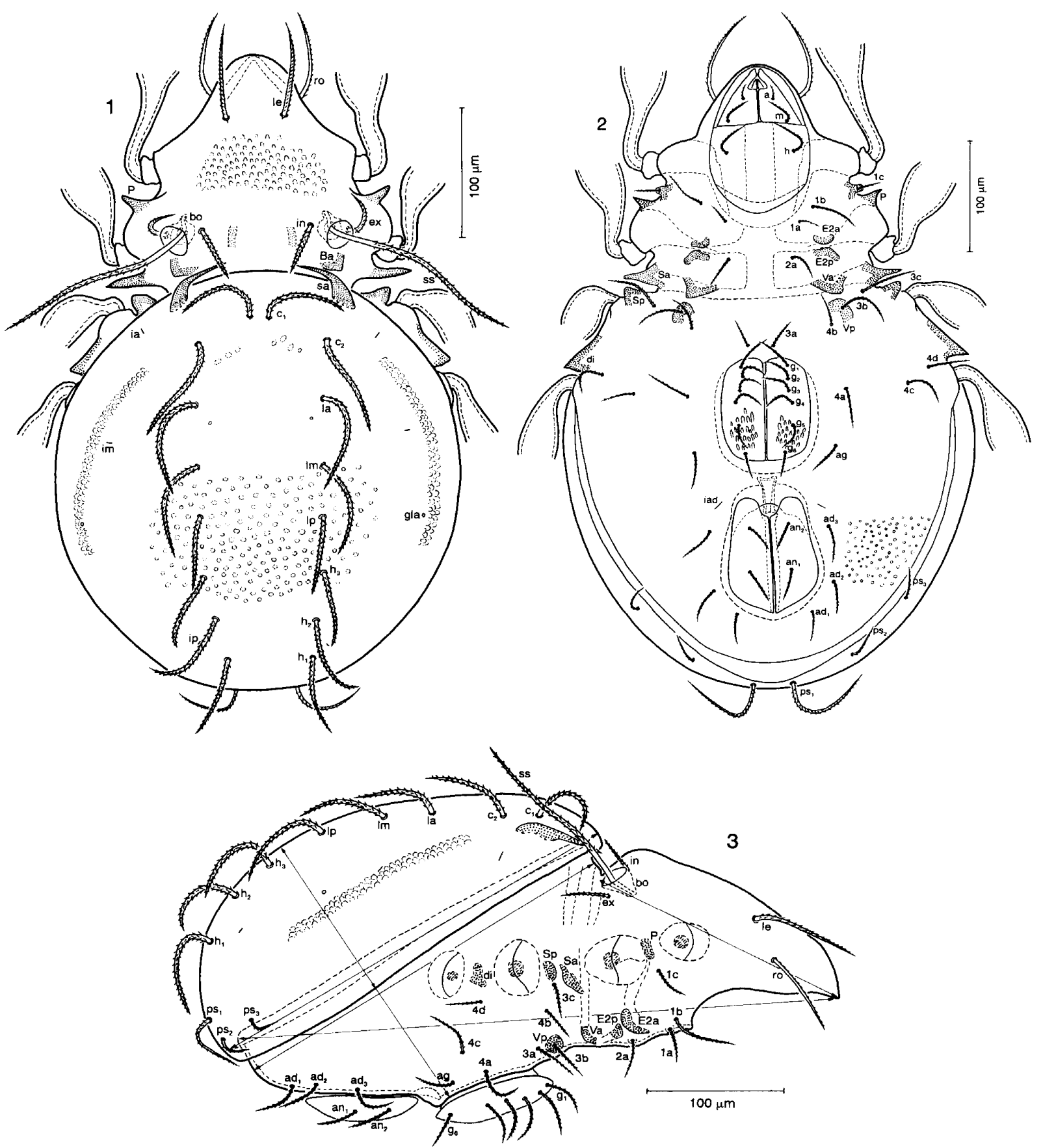

Figs 1-3. Epidamaeus granulatus sp. nov. 1. Dorsal aspect. 2. Ventral aspect. 3. Lateral aspect, legs removed. Setation and other structural elements of body are labeled following BehanPelletier and Norton $(1983,1985)$.

Porose areas of femora I-IV and trochantera III and IV inconspicuous. Formula of leg setation (including famulus): I (1-7-4-4-20); II (1-6-4-4-16); III (3-4-3-3-16); IV (1-4-3-314); formula of solenidia: I (1-2-2); II (1-1-2); III (1-1-0); IV (0-1-0). Structure and setation of legs I-IV as shown in Figs 6-10.

Material examined. Holotype (female) and 8 paratypes (5 males and 3 fe- 

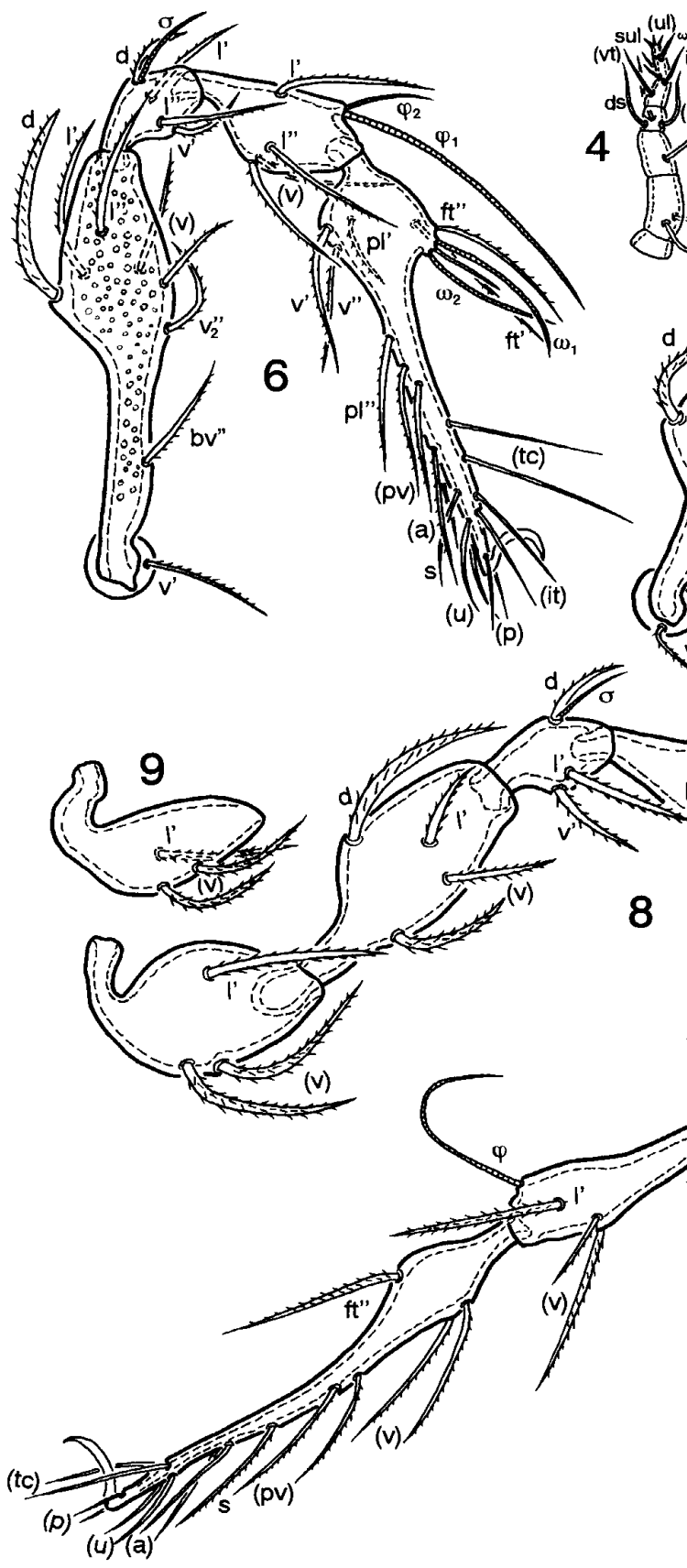

8

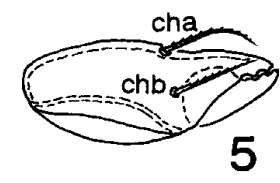

5
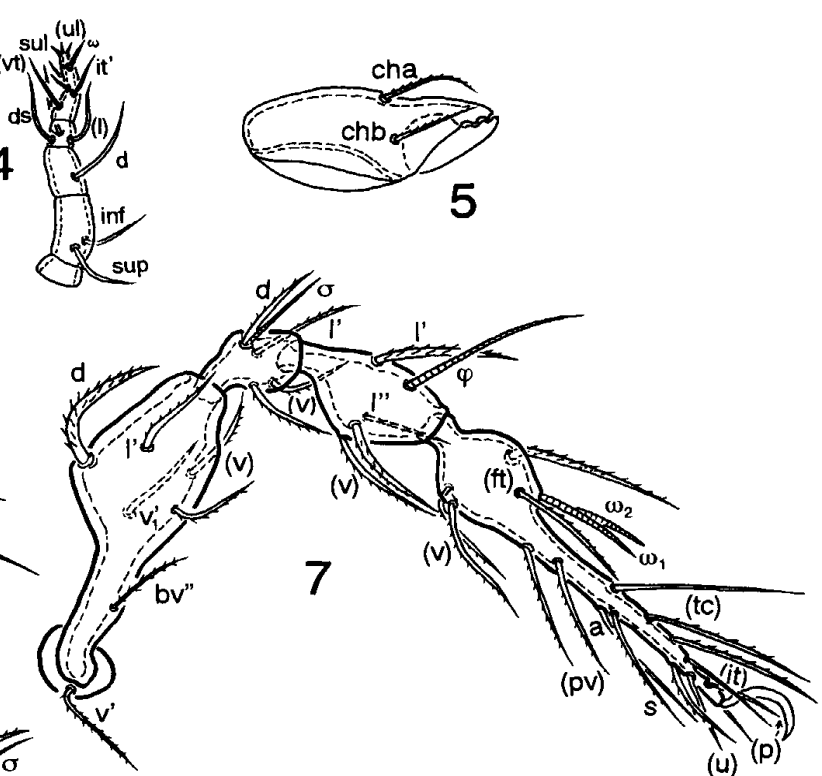

(u)
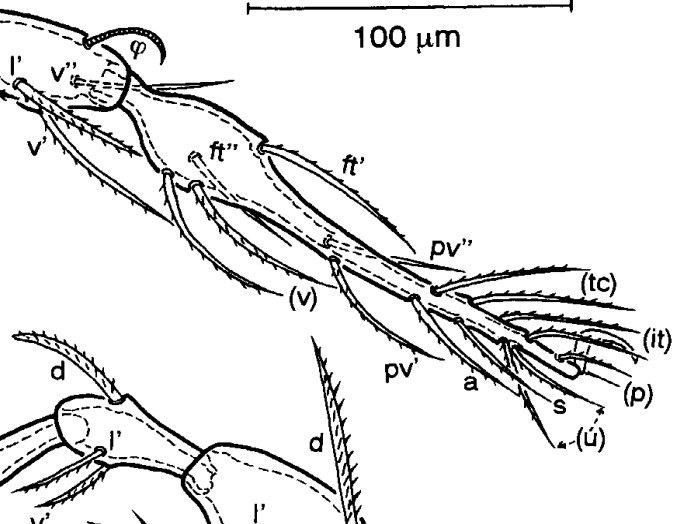

10
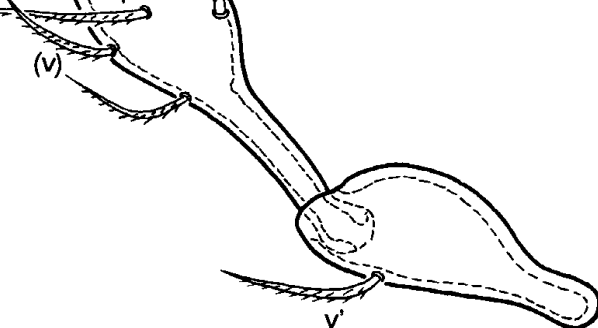

Figs 4-10. Epidamaeus granulatus sp. nov. 4. Palp (left, antiaxial aspect). 5. Chelicera (right, antiaxial aspect). 6. Leg I (right, antiaxial aspect). 7. Leg II (right, antiaxial aspect). 8. Leg III (left, antiaxial aspect). 9. Trochanter of leg III (right, paraxial aspect). 10. Leg IV (left, antiaxial aspect). Leg setation are labeled following Norton (1977a, b).

males): Mt. Khustai, Altanbulag District, Central Province, litter of birch forest (Betula platyphylla Sukatchev, 1911), $47^{\circ} 42^{\prime} \mathrm{N}, 106^{\circ} 25^{\prime} \mathrm{E}, 1680 \mathrm{~m}$ above sea level, 11-IV-1996, Leg. B. Bayartogtokh.

Type depository. The holotype and six paratypes are deposited in the collection of the Department of Zoology, National University of Mongolia, Ulaanbaatar, Mongolia, and two paratypes (NSMT-Ac 11143, 11144) are deposited in the National 
Table 1. Length of leg segments of Epidamaeus granulatus sp. nov. $(\mu \mathrm{m})$

\begin{tabular}{lccccc}
\hline Legs & Trochanter & Femur & Genu & Tibia & Tarsus \\
\hline I & - & 127 & 38 & 61 & 157 \\
II & - & 112 & 36 & 56 & 132 \\
III & 76 & 102 & 46 & 71 & 178 \\
IV & 86 & 147 & 56 & 107 & 213 \\
\hline
\end{tabular}

Science Museum, Tokyo, Japan. All specimens are preserved in alcohol.

Remarks. Among the known species of the nominate subgenus Epidamaeus, the following species resemble the new species in having of well-developed propodolateral apophyses: E. tecticola (Michael, 1888), E. bakeri (Hammer, 1952), E. mackenziensis (Hammer, 1952), E. nasutus Behan-Pelletier and Norton, 1985, E. verrucatus Enami and Fujikawa, 1989, E. fragilis Enami and Fujikawa, 1989, E. yunnanensis Enami, Aoki and Hu, 1994, and E. johnstoni Tolstikov, 1997. However, E. granulatus sp. nov. is easily distinguishable from all the above species by the presence of three setae on trochanter III, the strongly curved, anteromedially directed spinae adnatae, and the very thick and strongly barbed notogastral setae. This is the first species of Epidamaeus known to have three setae on trochanter III. Besides these principal diagnostic features, the new species can also be distinguished from each species mentioned above in several certain other characters.

Thus, E. granulatus sp. nov. differs from $E$. tecticola described by Michael (1888) and redescribed by Luxton (1989) from Great Britain in 1) the strongly barbed sensilli, interlamellar setae, and notogastral setae; 2) the far larger size of the spinae adnatae; 3) the rostral seta inserted on the lateral side of the rostrum (in E. tecticola seta ro is situated on the dorsal side of the prodorsum); 4) the lamellar seta situated rather centrally as opposed to the more lateral situation in $E$. tecticola; 5$)$ the presence of a distinct ventro-distal projection or protectum on trochanter IV, and 6) the far smaller body size (E. tecticola $650-670 \mu \mathrm{m}$ long).

The new species is different from the two North American species $E$. bakeri and E. mackenziensis, described by Hammer (1952) from Canada and later redescribed by Behan-Pelletier and Norton (1983) and from E. nasutus, described by Behan-Pelletier and Norton (1985) from Alaska, in 1) the relatively small, slender, and narrowly projecting propodolateral apophyses (apophyses $P$ in the three compared species very strong and not projecting distally, but broadly rounded); 2) the strongly barbed and thick sensilli and interlamellar, exobothridial, and notogastral setae (the sensilli and all dorsal setae of the North American species are very thin and smooth or rarely very weakly barbed); 3) the far larger size of the spinae adnatae as opposed to the very small $s a$ in the compared species; 4 ) the presence of well-developed tubercles $E 2 a$ and $E 2 p$; 5$)$ the conspicuously barbed hypostomal, epimeral, and ano-genital setae; and 6) the different number of setae on tarsi II and III and femora I and III.

The two Japanese species E. verrucatus and E. fragilis, described by Enami and Fujikawa (1989), can be distinguished from the present new species by 1) the very long and flagellate sensilli; 2) the distinct undulations on the anterodorsal part of acetabulum I; 3 ) the well-developed tubercles situated anterior (E. verrucatus) or posterior (E. fragilis) to the bothridia; 4) the very long rostral, lamellar, in- 
terlamellar (E. verrucatus), and notogastral (E. fragilis) setae; 5) the absence of tubercles $V p, E 2 a$, and $E 2 p$; and 6) the different number of setae on tarsi I, II, and III.

The Chinese species E. yunnanensis, described by Enami, Aoki and $\mathrm{Hu}$ (1994), differs from $E$. granulatus sp. nov. in 1) the very long, smooth, and flagellate sensilli; 2) the thin and smooth prodorsal setae and minutely barbed notogastral setae; 3 ) the long, smooth, flagellate pseudanal setae $p s_{1}$; 4) the absence of tubercles $V p$, $E 2 a$, and $E 2 p$; 5) the smooth ventral setae; and 6) the presence of the tubercle $L a$.

The last species, E. johnstoni described by Tolstikov (1997) from Kazakhstan, is easily distinguishable from $E$. granulatus sp. nov. by 1) the very long, flagellate sensilli and notogastral setae; 2) the very short interlamellar setae; 3 ) the relatively short and blunt propodolateral apophyses; 4) the very small spinae adnatae; 5) the short and smooth ventral setae; and 6) the different number of setae on tarsi II and III.

Etymology. The specific name "granulatus" is a Latin adjective meaning granulated; it refers to the numerous granules on the dorsal and ventral plates and leg segments.

Epidamaeus culterisetosus sp. nov.

(Figs 11-19)

Diagnosis. Relatively small species; propodolateral apophyses $P$ absent; prodorsal tubercle $B a$ present, but tubercles $B p, D a$, and $D p$ absent; sensilli long, distinctly expanded distally, distal part with dense, minute barbs; notogastral setae thick, mostly smooth (except $p s_{1}, p s_{2}$, and $p s_{3}$ ), nearly table-knife-shaped, darkly pigmented, only proximal part lighter in color and slightly thinner than more distal parts; pseudanal setae $\left(p s_{1}, p s_{2}\right.$, and $\left.p s_{3}\right)$ distinctly thinner and far longer than others, with a few minute barbs; spinae adnatae large, slightly curved anteromediad; enantiophyses $E 2, V$, and $S$ well developed; epimeral regions III and IV with three and four setae, respectively; tarsi I, II, and III with 19, 18, and 17 setae, respectively; leg IV about 1.2 times longer than body.

Measurements. Body length 472-437 (455) $\mu \mathrm{m}$; proterosomal length 188-193 (191) $\mu \mathrm{m}$; proterosomal width 183-193 (188) $\mu \mathrm{m}$; hysterosomal length 289-315 (302) $\mu \mathrm{m}$; notogastral length 366-375 (371) $\mu \mathrm{m}$; notogastral width 289-315 (302) $\mu \mathrm{m}$.

Description. Integument. Reddish-brown to deep reddish brown in color. Surface of dorsal and ventral plates of body and leg segments with rather thick cerotegument. Conspicuously microtuberculate on all tubercles, on lateral part of podosoma, and around leg acetabula. Notogaster with exuvial scalps, and all leg segments with rough adherent debris.

Prodorsum. Rostrum rounded in dorsal view, but in lateral view slightly projected anteroventrad. Rostral seta long (61-66 (63) $\mu \mathrm{m})$, sparsely barbed unilaterally. Lamellar seta slightly longer than ro $(82-89(86) \mu \mathrm{m})$, sparsely barbed unilaterally. Interlamellar seta slightly shorter (58-64 (61) $\mu \mathrm{m})$ but more strongly barbed than ro or $l e$, slightly darkly pigmented. Exobothridial setae long (53-61 (56) $\mu \mathrm{m})$ but thin, densely barbed. Sensillus long (139-144 (142) $\mu \mathrm{m})$, thinner in its proximal half but thicker distally; distal half with dense, minute barbs. Bothridium with large opening, directed posterolaterad. Tubercles $B p, D a$, and $D p$ absent; pair of tubercles $B a$ large, widely spaced from each other and situated posterior to each 


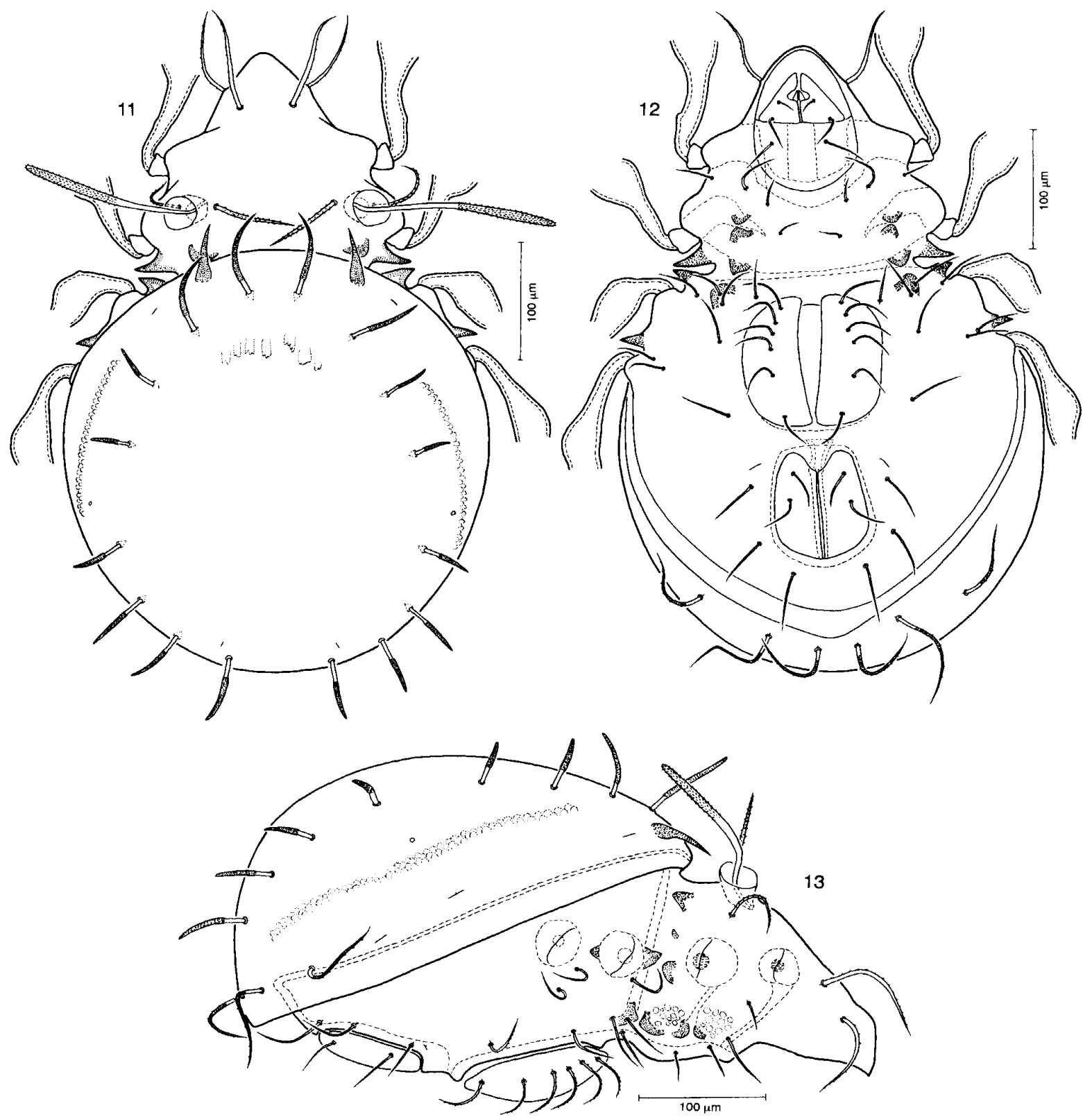

Figs 11-13. Epidamaeus culterisetosus sp. nov. 11. Dorsal aspect. 12. Ventral aspect. 13. Lateral aspect.

bothridium. Propodolateral apophyses $P$ absent (Fig. 11).

Notogaster. Almost circular, about 1.05 times as long as wide. Hysterosomal dorso-ventral thickness $259 \mu \mathrm{m}$; notogastral thickness $183 \mu \mathrm{m}$. Spinae adnatae large $(51 \mu \mathrm{m})$, slightly curved anteromediad; distance between their bases approximately equal to that between tubercles $B a-B a$. Notogastral setae of $c, l$, and $h$ series smooth (31-43 $\mu \mathrm{m})$, nearly table-knife-shaped, mostly darkly pigmented, with proximal part of seta lighter in color and slightly thinner than distal part; pseudanal setae, $p s_{1}, p s_{2}$, and $p s_{3}$ thinner and far longer $(71-78 \mu \mathrm{m})$ than others, with a few minute barbs (Figs 11-13). Setae $c_{1}, c_{2}, l a$, and $l m$ directed anterolaterad, other setae directed posterior or posterolaterad. Lyrifissures ia, ih, ips, and ip and latero- 


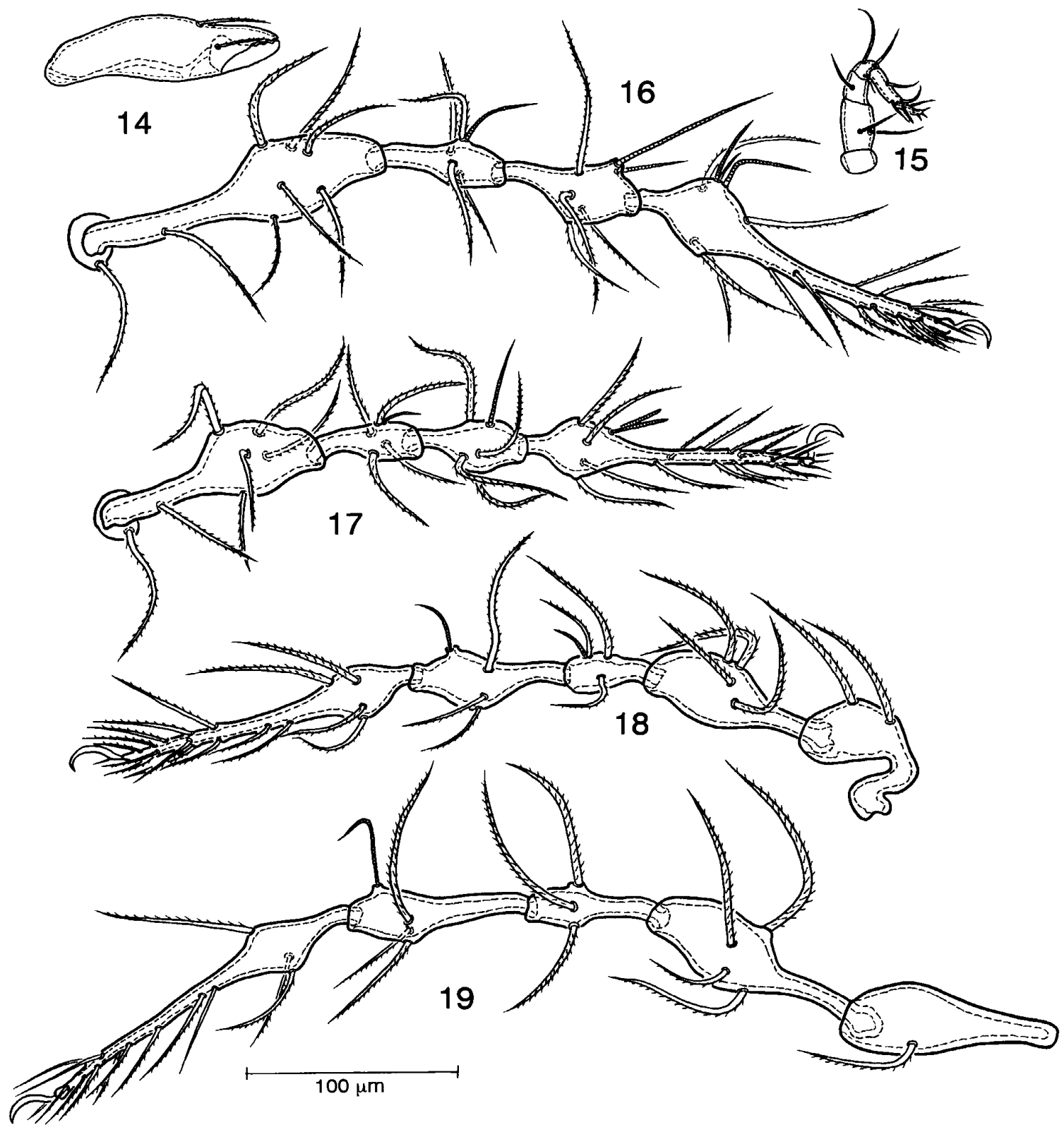

Figs 14-19. Epidamaeus culterisetosus sp. nov. 14. Chelicera (right, antiaxial aspect). 15. Palp (left, antiaxial aspect). 16. Leg I (right, antiaxial aspect). 17. Leg II (right, antiaxial aspect). 18. Leg III (right, paraxial aspect). 19. Leg IV (right, paraxial aspect).

opisthosomal gland opening well developed; lyrifissures im inconspicuous (Figs 11, 13).

Gnathosoma. Infracapitular mentum slightly longer than wide, without noticeable microtubercles. Hypostomal setae $h$ and $m$ long, setae $a$ short, smooth (Fig. 12). Chelicerae slender, $112 \mu \mathrm{m}$ in length, fixed and movable digits with three blunt teeth on each. Trägårdh's organ inconspicuous; setae cha and chb conspicuously barbed (Fig. 14). Palp slender, $96 \mu \mathrm{m}$ in length; palpal setation: 0-2-1-3-8, including solenidion $\omega$ (Fig. 15).

Epimeral region. Tectum of podocephalic fossa broadly rounded. Tubercles 
Table 2. Length of leg segments of Epidamaeus culterisetosus sp. nov. ( $\mu \mathrm{m})$

\begin{tabular}{lccccc}
\hline Legs & Trochanter & Femur & Genu & Tibia & Tarsus \\
\hline I & - & 147 & 61 & 71 & 168 \\
II & - & 107 & 48 & 61 & 142 \\
III & 56 & 91 & 46 & 66 & 147 \\
IV & 102 & 122 & 66 & 97 & 178 \\
\hline
\end{tabular}

$E 2 a$ and $E 2 p$ situated very close to each other; $S a$ and $S p$ subtriangular in shape, distinctly pointed distally; $V a$ and $V p$ strongly developed, broadly rounded to subtriangular; $V p$ bearing epimeral seta $3 b$. Discidium well developed, narrowly triangular, distinctly pointed distally. Epimeral setae long, smooth, setae $1 a, 1 c$, and $2 a$ conspicuously shorter than others; setal formula: 3-1-3-4 (Fig. 12).

Ano-genital region. Normal for genus, genital opening much larger than anal one. Ano-genital setae long, smooth. Adanal lyrifissure situated obliquely, at a level a little anterior to adanal setae $a d_{3}$ (Fig. 12).

Legs. Lengths of leg segments shown in Table 2. Seta $d$ on genu I a little shorter than its coupled solenidion $\sigma$, but in legs II and III this seta about twice as long as solenidia $\sigma$. Porose areas of femora I-IV and trochantera III and IV inconspicuous. Formula of leg setation (including famulus): I (1-7-4-4-19); II (1-6-4-4-18); III (2-4-3-317); IV (1-4-3-3-14); formula of solenidia: I (1-2-2); II (1-1-2); III (1-1-0); IV (0-1-0). Structure and setation of legs I-IV as shown in Figs 16-19.

Material examined. Holotype (female) and 3 paratypes ( 1 female and 2 males): Mt. Khustai, Altanbulag District, Central Province, soils of mountain steppe (Stipa grandis P. Smimov, 1929), $47^{\circ} 42^{\prime} \mathrm{N}, 106^{\circ} 25^{\prime} \mathrm{E}, 1620 \mathrm{~m}$ above sea level, 11-IV-1996, Leg. B. Bayartogtokh.

Type depository. The holotype and a paratype are deposited in the Department of Zoology, National University of Mongolia, Ulaanbaatar, Mongolia, and two paratypes (NSMT-Ac 11145, 11146) are deposited in the National Science Museum, Tokyo, Japan. All specimens are preserved in alcohol.

Remarks. The new species $E$. culterisetosus can be readily distinguished from all the known species of Epidamaeus by the table-knife-like notogastral setae of the $d, l$, and $h$ series and the distally expanded sensilli. Among the known species of Epidamaeus, only E. tritylos described by Behan-Pelletier and Norton (1983) from the former Soviet Union and Alaska is somewhat similar to E. culterisetosus sp. nov. in these characters. However, E. tritylos is easily distinguishable from $E$. culterisetosus sp. nov. by 1) the well-developed prodorsal tubercles $D a$ and $B p ; 2$ ) the relatively short and poorly expanded sensillus; 3 ) the relatively short and distally rounded tubercles $S p ; 4)$ the different (lateral) direction of the spinae adnatae; 5 ) the proximally widened and not darkly pigmented notogastral setae; 6) the shortness of setae $p s_{1}, p s_{2}$, and $\left.p s_{3} ; 7\right)$ the distinctly barbed epimeral and ano-genital setae; and 8) the different number of setae on tarsi I, III, and IV.

Etymology. The specific name combining "culter" and "setosus" is taken 


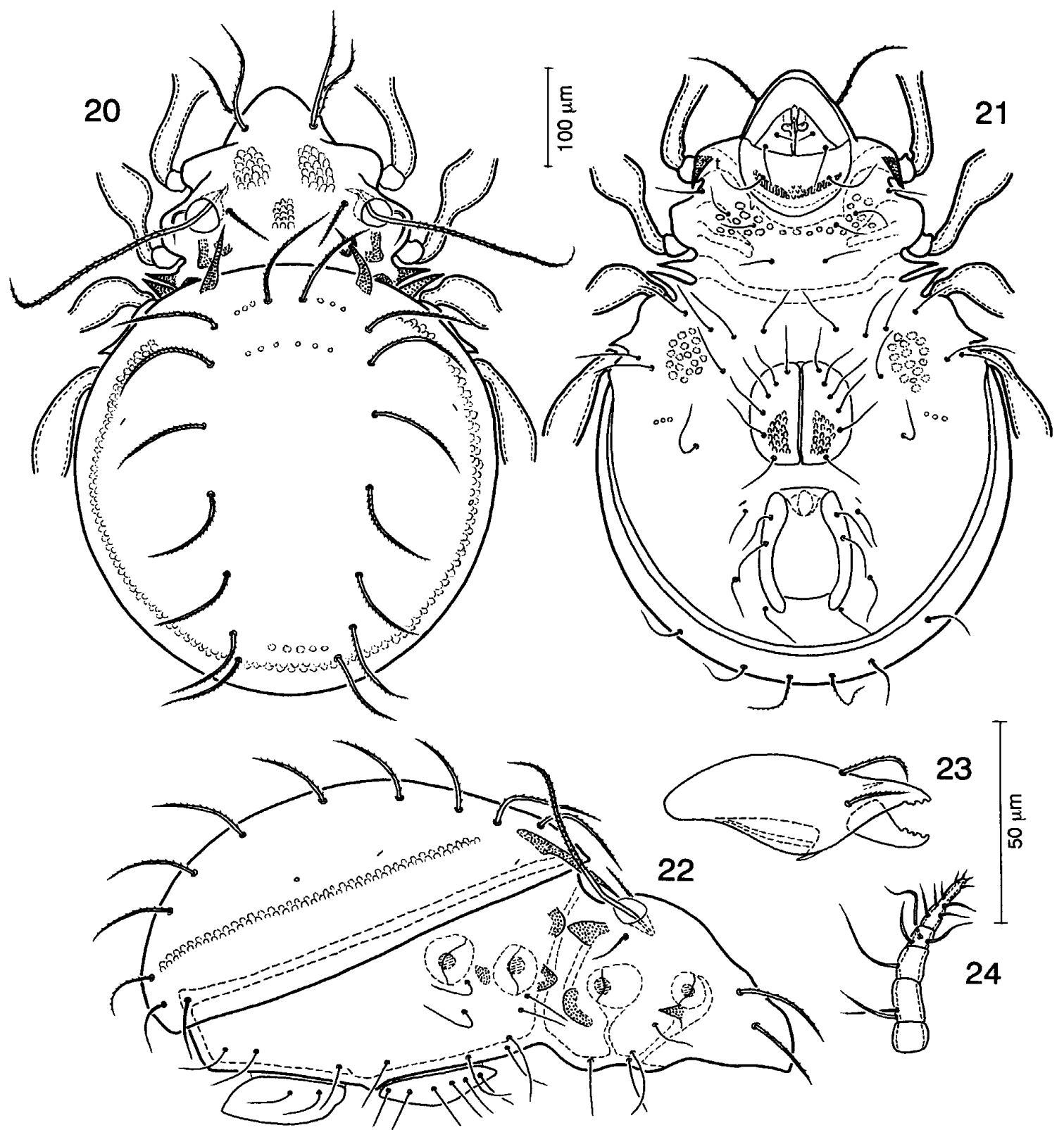

Figs 20-24. Epidamaeus mongolicus sp. nov. 20. Dorsal aspect. 21. Ventral aspect. 22. Lateral aspect. 23. Chelicera (right, antiaxial aspect). 24. Palp (left, antiaxial aspect).

from the Latin meaning 'knife' and 'bristly', respectively, and refers to the tableknife-like notogastral setae of the $c, l$, and $h$ series.

Epidamaeus mongolicus sp. nov.

(Figs 20-33)

Diagnosis. Medium in size; propodolateral apophyses $P$ absent; tubercles $D a$, $B a$, and $B p$ present, tubercle $D p$ absent; sensilli long, tapering distally, with 
minute barbs, tip slightly flagellate; notogastral setae relatively thin, minutely barbed (except smooth $p s_{2}$ and $p s_{3}$ ), darkly pigmented; setae $p s_{1}, p s_{2}$, and $p s_{3}$ thinner than the others; $p s_{1}$ with a few minute barbs; $p s_{2}$ and $p s_{3}$ smooth; spinae adnatae long; tectum of podocephalic fossa strongly developed, produced laterally as a strong teeth overhanging trochanter I; enantiophyses $E 2$ and $V$ absent; $S$ well developed; epimeral regions III and IV with three and four setae, respectively; tarsus I with 20 setae; both tarsi II and III with 17 setae; leg IV about 1.4 times longer than body length.

Measurements. Body length 559-610 (587) $\mu \mathrm{m}$; proterosomal length 223-229 (226) $\mu \mathrm{m}$; proterosomal width 234-239 (236) $\mu \mathrm{m}$; hysterosomal length 376-401 (391) $\mu \mathrm{m}$; notogastral length 422-442 (434) $\mu \mathrm{m}$; notogastral width 381-391 (386) $\mu \mathrm{m}$.

Description. Integument. Reddish-brown to deep reddish brown in color. Surface of dorsal and ventral plates of body and leg segments with relatively thin cerotegument. Conspicuously microtuberculate on all enantiophyses and tubercles, on lateral part of podosoma, and around leg acetabula. Notogaster without exuvial scalps; leg segments with loosely attached adherent debris.

Prodorsum. Rostrum rounded in dorsal view, but in lateral view slightly projected anteroventrad. Rostral seta long (66-76 (71) $\mu \mathrm{m})$, weakly barbed. Lamellar seta longer than ro (91-97 (94) $\mu \mathrm{m}$ ), weakly barbed. Interlamellar seta thin, short (54-66 (59) $\mu \mathrm{m}$ ), finely barbed. Exobothridial seta thin, approximately as long as in, but thinner, minutely barbed unilaterally. Sensillus very long (221-244 (233) $\mu \mathrm{m})$, thin, with minute barbs (Figs $20,22,26$ ). Tubercles $B a, B p$, and $D a$ well developed; $D p$ absent. Tubercle $B a$ large; $D a$ smaller than the former; $B p$ large, sometimes its posterior part concealed under anterior margin of notogaster. Propodolateral apophyses $P$ absent (Figs 20, 22, 25).

Notogaster. Slightly oval, about 1.08 times as long as wide. Dorso-ventral thickness of hysterosoma $305 \mu \mathrm{m}$; thickness of notogaster $168 \mu \mathrm{m}$. Spinae adnatae long $(107 \mu \mathrm{m})$, slightly curved anteromediad; distance between their bases slightly larger than that between tubercles $D a-D a$. Notogastral setae relatively thin; setae of $c, l$, and $h$ series $(97-122 \mu \mathrm{m})$ minutely barbed, darkly pigmented; setae $p s_{1}, p s_{2}$, and $p s_{3}$ distinctly thinner and slightly shorter $(79-87 \mu \mathrm{m})$ than others; $p s_{1}$ with a few and minute barbs; $p s_{2}$ and $p s_{3}$ smooth (Figs 20-22, 25). Setae $c_{1}, c_{2}$, and la directed anterolaterad, other setae directed posterior or posterolaterad. Lyrifissures ia and im and latero-opisthosomal gland opening well developed; other lyrifissures inconspicuous (Figs 22, 25).

Gnathosoma. Infracapitular mentum slightly wider than long, with a few microtubercles. Hypostomal setae smooth, $h$ and $m$ very long, setae $a$ very short (Figs 21,28 ). Chelicerae strong; fixed and movable digits with four blunt teeth on each. Trägårdh's organ conspicuous; setae cha and chb conspicuously barbed (Fig. 23). Palp slender, palpal setation: 0-2-1-3-9, including solenidion $\omega$ (Fig. 24).

Epimeral region. Tectum of podocephalic fossa strongly developed, produced laterally as a strong tooth $(t)$ overhanging trochanter I and its distal end well extending beyond the posterior margin of trochanter I. Enantiophyses $V$ and $E 2 \mathrm{ab}-$ sent. Tubercles $S a$ and $S p$ narrowly triangular and distinctly pointed distally. Discidium subtriangular, pointed distally, shorter than tubercles $S a$ and $S p$. Epimeral setae long, smooth; setal formula: 3-1-3-4.

Ano-genital region. Normal for genus, genital and anal plates approximately same in size. Ano-genital setae long, smooth. Adanal lyrifissure situated at a level 


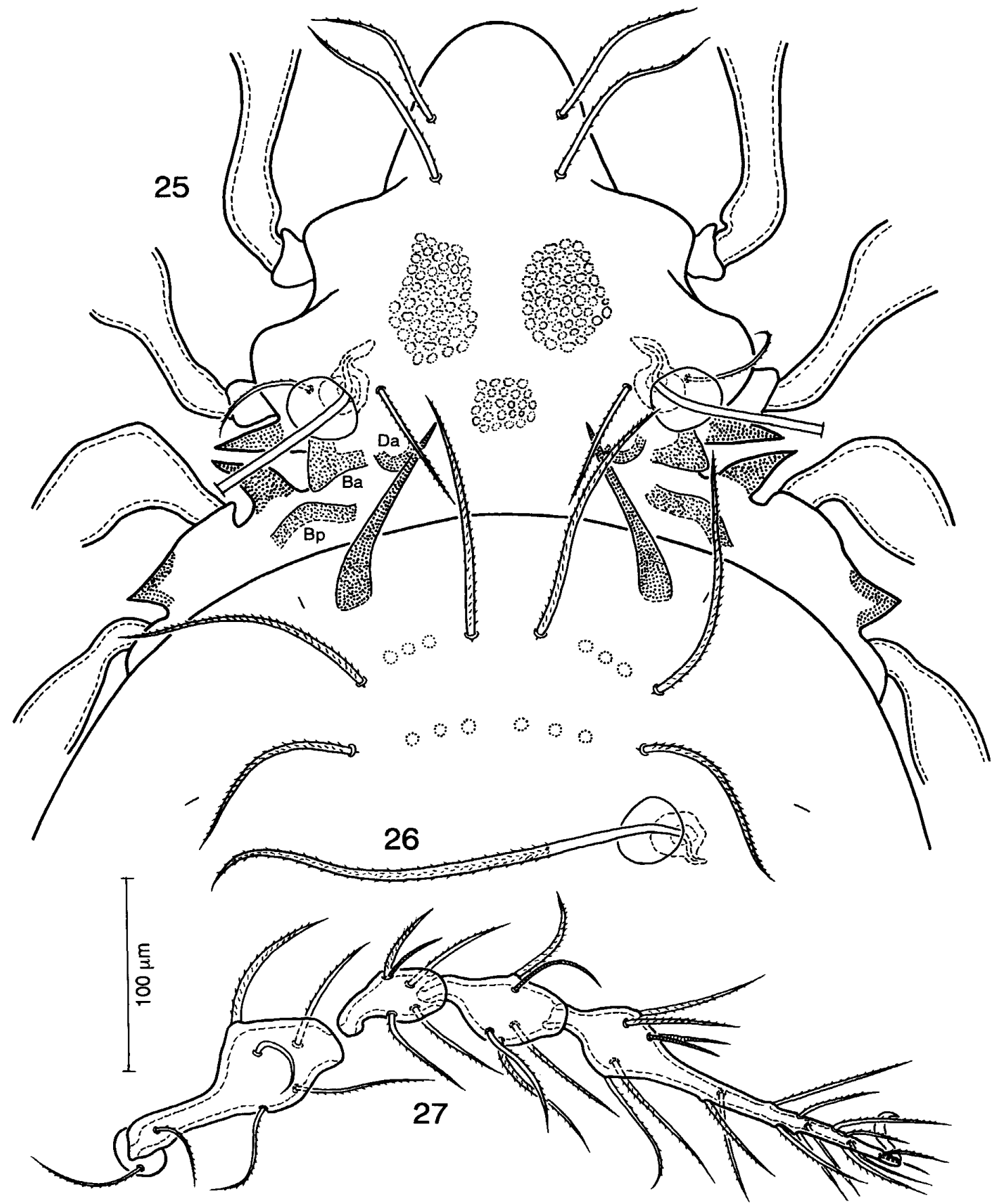

Figs 25-27. Epidamaeus mongolicus sp. nov. 25. Prodorsum and anterior part of notogaster. Tubercles are labeled following Behan-Pelletier and Norton (1983, 1985). 26. Sensillus and bothridium. 27. Leg II (right, antiaxial aspect).

a little anterior to adanal setae $a d_{3}$ (Figs 21, 28).

Legs. Lengths of leg segments shown in Table 3. Setae $d$ on genua I-III a little longer and much stronger than their coupled solenidia $\sigma$. Seta $d$ of femora I-VI, $l$ of genua and trochantera III and IV very long, thick and with very strong barbs. Formula of leg setation (including famulus): I (1-7-4-4-20); II (1-6-4-4-17); III (2-4-3-3-17); 
Table 3. Length of leg segments of Epidamaeus mongolicus sp. nov. ( $\mu \mathrm{m})$

\begin{tabular}{lccccc}
\hline Legs & Trochanter & Femur & Genu & Tibia & Tarsus \\
\hline I & - & 188 & 76 & 91 & 221 \\
II & - & 117 & 56 & 71 & 188 \\
III & 61 & 117 & 66 & 102 & 203 \\
IV & 137 & 183 & 86 & 152 & 274 \\
\hline
\end{tabular}

IV (1-4-3-3-14); formula of solenidia: I (1-2-2); II (1-1-2); III (1-1-0); IV (0-1-0). Structure and setation of legs I-IV as shown in Figs 27, 29-33.

Material examined. Holotype (male) and 8 paratypes (4 females and 4 males): Mt. Bogd Khan, Central Province, $6 \mathrm{~km}$ south of Ulaanbaatar, litter of larch forest (Larix sibirica Ledebour, 1833), $47^{\circ} 55^{\prime} \mathrm{N}, 106^{\circ} 30^{\prime} \mathrm{E}, 1780 \mathrm{~m}$ above sea level, 06-X-1996, Leg. B. Bayartogtokh.

Type depository. The holotype and six paratypes are deposited in the Department of Zoology, National University of Mongolia, Ulaanbaatar, Mongolia, and two paratypes (NSMT-AC 11147, 11148) are deposited in the National Science Museum, Tokyo, Japan. All specimens are preserved in alcohol.

Remarks. Epidamaeus mongolicus sp. nov. can be readily distinguished from most other species of Epidamaeus by the strongly developed tectum of the podocephalic fossa, the presence of three pairs of well developed prodorsal tubercles $(B a, B b$, and $D a)$, and the absence of the ventral tubercles $E 2 a, E 2 p, V a$, and $V p$. Among the known species of the genus Epidamaeus, only E. mackenziensis and $E$. bakeri, described by Hammer (1952) from Canada and later redescribed by Behan-Pelletier and Norton (1983), have a strongly developed tectum of the podocephalic fossa. However, both the Canadian species are easily distinguishable from the new species by 1) the well developed propodolateral apophyses; 2) the much smaller spinae adnatae; 3) the absence of tubercles $B p$ and $D a$; 4) the presence of well developed tubercles $E 2 a$ and $E 2 p$; and 5) the relatively short and distally rounded tubercle $S p$.

Concerning the prodorsal tubercles, only E. trytilos described by Behan-Pelletier and Norton (1983) from the former Soviet Union and Alaska is somewhat similar to $E$. mongolicus sp. nov. in the presence of tubercles $B a, B p$, and $D a$. However, E. trytilos can be differentiated from the new species in 1) the far shorter and thicker sensilli and interlamellar setae; 2 ) the smooth, short, and very thick notogastral setae; 3 ) the different arrangement of the notogastral setae (setae $l$ and $h$ series of $E$. trytilos situated marginally); 4) the presence of the well developed enantiophyses $E 2$ and $V$; 5) the relatively shorter and distally rounded tubercle $S p$; and 6) the conspicuously barbed hypostomal, epimeral, and ano-genital setae.

The complete absence of tubercles $E 2 a, E 2 p, V a$, and $V p$ is one of the unique features of this new species, because most of the known species of Epidamaeus have at least one pair of ventral tubercles.

Etymology. The specific name "mongolicus" refers to the region encompassing the type locality of this species. 


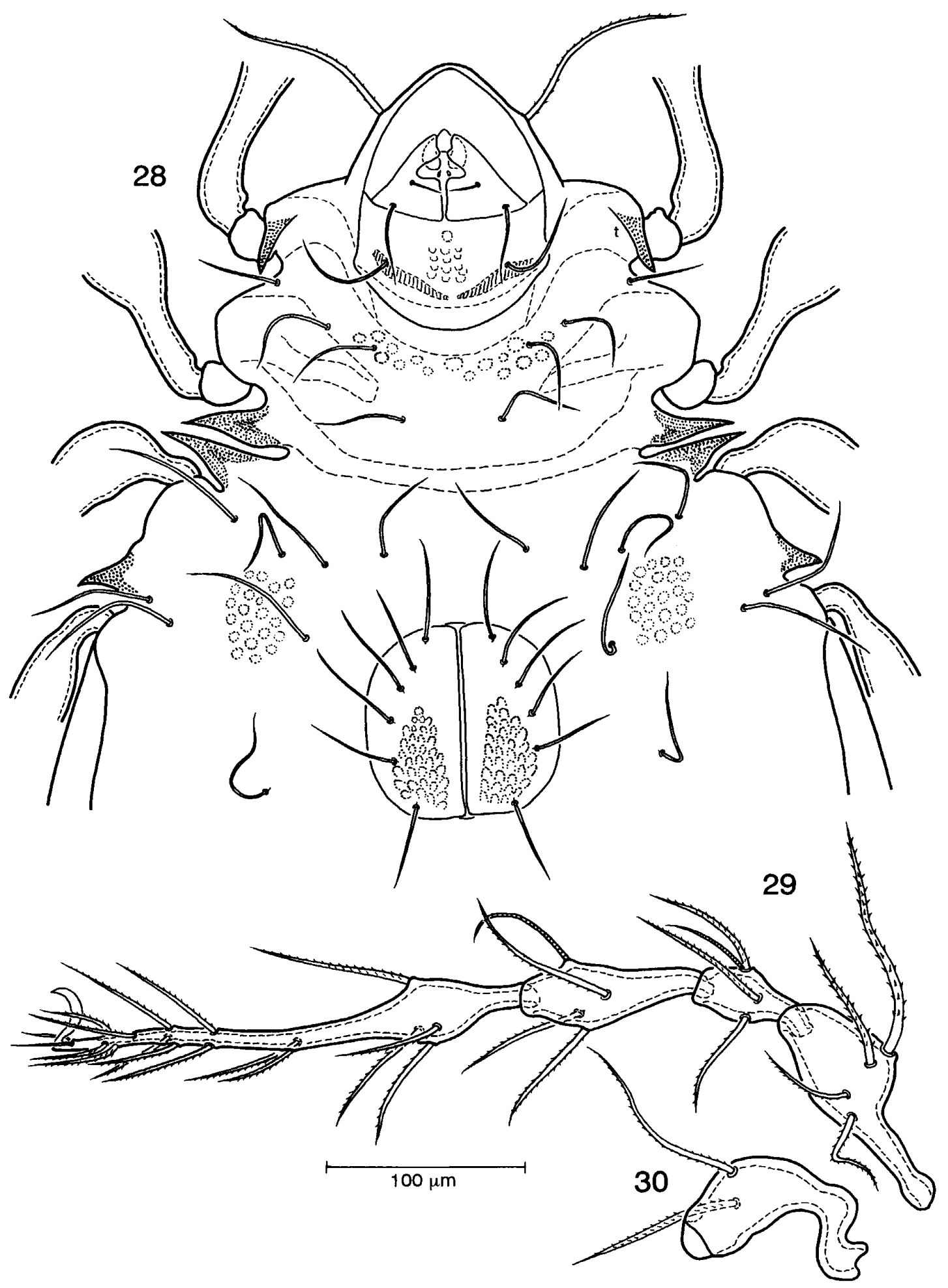

Figs 28-30. Epidamaeus mongolicus sp. nov. 28. Gnathosomal, epimeral, and genital regions. 29. Leg III (right, paraxial aspect). 30. Trochanter III (right, paraxial aspect). 


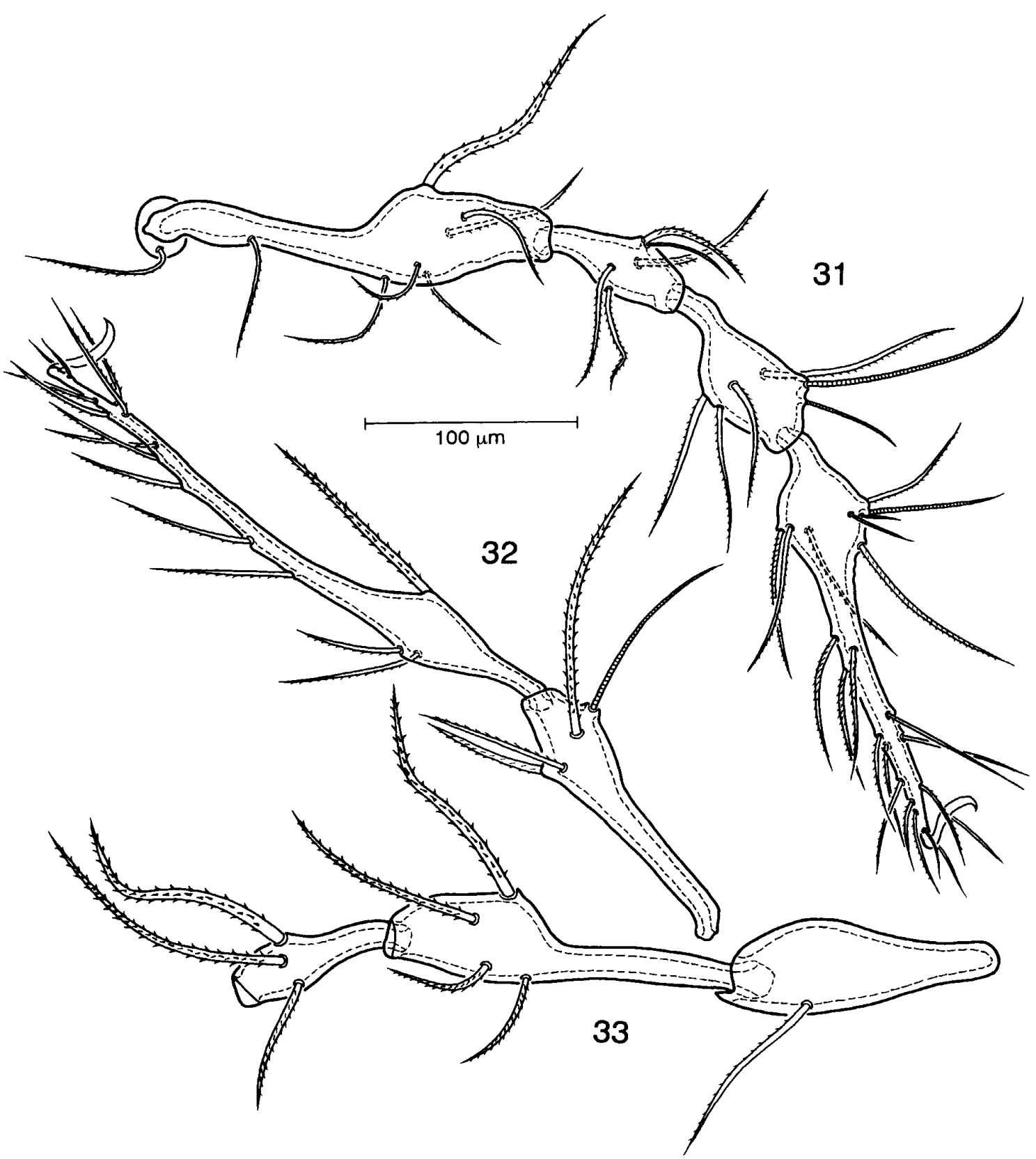

Figs 31-33. Epidamaeus mongolicus sp. nov. 31. Leg I (right, antiaxial aspect). 32. Tibia and tarsus IV (right, paraxial aspect). 33. Trochanter, femur, and genu IV (right, paraxial aspect).

\section{Discussion}

According to my survey of the literature, 74 named species (including three new species, described here) belong to the genus Epidamaeus. Among them 69 species are included in the nominate subgenus Epidamaeus and five species in the subgenus Akrodamaeus. The taxonomic status of two Russian species, $E$. paraspinosus Bulanova-Zachvatkina, 1974 and E. plumosus Bulanova-Zachvatkina, 1974 , is uncertain, and I could not find the original descriptions of these species. In the identification key of Russian oribatid mites, Bulanova-Zachvatkina (1975) in- 
cluded short characterizations of these two species without any figures, and there was no citation of her work of 1974. I suppose that the descriptions of these species have not been published. If so, these names should be unavailable. Further study is necessary to clarify the taxonomic status of these two species.

On the basis of the presence or absence of propodolateral apophyses $P$, the members of the nominate subgenus Epidamaeus can be divided into two groups. The first group includes such species as E. tecticola (Michael, 1888), E. bakeri (Hammer, 1952), E. mackenziensis (Hammer, 1952), E. nasutus Behan-Pelletier and Norton, 1985, E. verrucatus Enami and Fujikawa, 1989, E. fragilis Enami and Fujikawa, 1989, E. yunnanensis Enami, Aoki and Hu, 1994, and E. granulatus sp. nov., which bear well-developed propodolateral apophyses. The remaining species belong to the second group, characterized by the absence of propodolateral apophyses. In the first group I have not included the Japanese species $E$. bacillum, E. folium, $E$. flexus, E. angulatus, and E. variabilis described by Fujikawa and Fujita (1985). In the original description, Fujikawa and Fujita mentioned that all of these species have propodolateral apophyses, but I disagree. These species have no distinctly developed apophyses $P$; the original figures given by Fujikawa and Fujita (1985) show the same contour of the rounded margin of the prodorsum as in the species I assign to the second group.

\section{Acknowledgements}

I would like to express my heartfelt thanks to Prof. Jun-ichi Aoki, Yokohama National University, Yokohama, Japan, for his valuable advice and helpful comments on the manuscript. Thanks are also due to the anonymous reviewers for their critical reading of the manuscript with many useful comments. This study was supported by the Japan Society for the Promotion of Science.

\section{References}

Behan-Pelletier, V. M. and Norton, R. A. 1983. Epidamaeus (Acari: Damaeidae) of arctic western North America and extreme northeast, U.S.S.R. Canadian Entomologist 115: 12531289.

Behan-Pelletier, V. M. and Norton, R. A. 1985. Epidamaeus (Acari: Damaeidae) of subarctic western North America and extreme northeastern USSR. Canadian Entomologist 117: 277-319.

Bulanova-Zachvatkina, E. M. 1975. Family Damaeidae. Pp. 121-131. In: Gilyarov, M. S. and Krivolutsky, D. A. (Eds) Opredelitel obitayushikh v pochve kleshei. Sarcoptiformes [A Key to the Soil-inhabiting Mites. Sarcoptiformes]. Nauka, Moscow, $491 \mathrm{pp}$. [In Russian]

Enami, Y. and Fujikawa, T. 1989. Two new species of the genus Epidamaeus (Acari: Damaeidae) from Japan. Edaphologia 40: 13-20.

Enami, Y., Aoki, J. and Hu, S. 1994. Oribatid mites from tropical forests of Yunnan province in China. Proceedings of the Japanese Society of Systematic Zoology (52): 43-46.

Fujikawa, T. and Fujita, M. 1985. Five new species belonging to the genus Epidamaeus from Nayoro of Hokkaido, north Japan (Oribatida). Edaphologia 32: 19-28.

Grandjean, F. 1960. Damaeus arvernensis n. sp. (Oribate). Acarologia 2: 250-275. 
Hammer, M. 1952. The microfauna of northern Canada. Part I. Oribatidae. Acta Arctica 4: $1-108$.

Luxton, M. 1989. Michael's British damaeids (Acari: Cryptostigmata). Journal of Natural History $23: 1367-1372$.

Michael, A. D. 1888. British Oribatidae. Volume II, pp. 337-657, Ray Society, London.

Norton, R. A. 1977a. A review of F. Grandjean's system of leg chaetotaxy in the Oribatei (Acari) and its application to the Damaeidae. pp. 33-62. In: Dindal, D. L. (Ed.) Biology of Oribatid Mites. State University of New York, College of Environmental Science and Forestry, Syracuse, New York, 122 pp.

Norton, R. A. 1977b. The genus Damaeus Koch (Acarina: Oribatei) in the eastern United States. Acarologia 19: 331-353.

Norton, R. A. 1978. Veloppia kananaskis n. sp. with notes on the familial affinities of Veloppia Hammer (Acari: Oribatei). International Journal of Acarology 4: 71-84.

Norton, R. A. 1979. Damaeidae (Acari: Oribatei) collected by the Hungarian Soil Zoological Expeditions to South America. Folia Entomologica Hungarica 32: 55 64 .

Tolstikov, A. V. 1997. Epidamaeus johnstoni: a new damaeid mite (Acariformes: Oribatei) from Kazakhstan. Acarologia 38: 199-203. 